MASCARENHAS, Fernando. Lazer: como prática da liberdade, uma proposta educativa para a juventude. 2. ed. Goiânia: Ed. da UFG, 2004.

Carolina Cavalcanti de Paula, Universidade do Estado de Goiás - UEG, Goiânia - Brasil

\title{
LAZER: COMO PRÁTICA DA LIBERDADE, UMA PROPOSTA EDUCATIVA PARA A JUVENTUDE
}

\section{RESUMO}

O presente trabalho consiste em uma resenha crítica do livro "Lazer como prática da liberdade: uma proposta educativa para a juventude", de Fernando Mascarenhas. $2^{\mathrm{a}}$ edição; Ed. da UFG, Goiânia-GO, 2004. Enfatizando a importância do lazer como reorganização da sociedade, através da construção de uma nova intervenção do lazer em grupos sociais, e escolhe como tal os meninos e meninas de Rua de Goiânia.

Palavras-Chave: Lazer; Reorganização da sociedade; Educação.

\section{LEISURE: THE PRACTICE OF FREEDOM, AN EDUCATIONAL PROPOSAL FOR YOUTH}

\begin{abstract}
This study is a critical review of the book "Leisure as a practice of freedom: an educational proposal for the youth," Fernando Mascarenhas. 2nd edition, publisher UFG, Goiania, GO, 2004. Emphasizing the importance of leisure as a reorganization of society, by building a new leisure intervention in social groups, and singles such as boys and girls from Street Goiânia.
\end{abstract}

Key-Word: Leisure, Reorganization of society, Education. 
Fernando Mascarenhas, iniciou seus estudos em Educação Física em 1989, na Universidade Federal de Juiz de Fora (UFJF), tendo se licenciado em 1992, pelo Centro Universitário de Volta Redonda (UNIFOA), em sua cidade natal. Possui Especialização em Filosofia Moderna e Contemporânea, realizada junto à Universidade Federal de São João Del-Rei (UFSJ), concluída em 1995. Mestrado e Doutorado em Educação Física, ambos realizados na Universidade Estadual de Campinas (Unicamp), concluídos em 1999 e 2005. Em sua trajetória profissional, foi professor do ensino básico no sistema público do Estado de Minas Gerais (SEE-MG), entre 1993 e 1996, e professor do ensino superior, tendo trabalhado na Universidade Federal de Minas Gerais (UFMG), em 1996, e na Universidade Federal de Goiás (UFG), entre 1997 e 2008. Desde 2009, é professor da Universidade de Brasília (UnB). Foi presidente, entre 2005 e 2009, do Colégio Brasileiro de Ciências do Esporte (CBCE), entidade científica representativa da área da Educação Física. Neste mesmo período, foi membro do Conselho Nacional de Esporte, orgão assessor do Ministério do Esporte. Atualmente, é coordenador do Programa de Pós-Graduação em Educação Física da UnB. No âmbito da produção científica, publicou em autoria e co-autoria vários trabalhos, dentre livros, capítulos de livro e artigos. Como professor, atuando no âmbito da graduação e da pósgraduação, desenvolve atividades de ensino, pesquisa e extensão vinculadas às seguintes linhas: Políticas de Esporte e Lazer; Educação Física, Formação e Trabalho. Coordena o Avante - Grupo de Pesquisa e Formação Sociocrítica em Educação Física, Esporte Lazer da UnB, integrando ainda o Necon - Núcleo de Estudos do Corpo e Natureza da UnB, o GEPELC - Grupo de Estudo e Pesquisa em Esporte, Lazer e Comunicação da UFG e o Observatório de Políticas de Educação Física, Esporte e Lazer da Unicamp.

O presente trabalho consiste em uma resenha do livro Lazer como prática da liberdade: uma proposta educativa para a juventude, de Fernando Mascarenhas. $2^{\text {a }}$ edição; Ed. da UFG, Goiânia-GO, 2004. O livro supracitado visa mostrar a importância do lazer como reorganização da sociedade, sendo assim o autor parte da construção de uma nova intervenção do lazer em grupos sociais, e escolhe como tal os meninos e meninas de rua de Goiânia. Para conseguir a emancipação do homem através dessa abordagem do lazer, Mascarenhas relata como foi possível essa nova prática, relatando os colaboradores e as dificuldades encontradas para a implementação do projeto. 
A princípio é necessário compreendermos as reflexões introdutórias acerca do lazer, e o presente autor inicia o livro buscando elucidar o lazer através do viés social ligado a prática educativa e refletir a estratégia de lazer junto aos grupos sociais e populares. A institucionalização do lazer contribuiu para sua disseminação e antes mesmo de haver uma formação específica no campo da graduação em educação física já havia a abordagem de temas ligados ao lazer. A partir da década de 1970 o lazer se desvincula da oportunidade de descanso e entretenimento, tornando-se direito social acessível a todos e promotor da formação de moral no individuo, ligada ao serviço social do comércio (SESC) voltada para a sociologia do lazer por meio de Joffre Dumazedier, cujo destaque está no "descanso", na “diversão" e no "desenvolvimento", caracterizando o lazer como atividades terciárias basicamente diferentes das tarefas de trabalho e dos deveres sociais.

Em 1980 surge uma nova abordagem para o lazer, vinculada a Nelson Carvalho Marcellino, enfatizando a necessidade de mudar o senso comum que havia no lazer. Tempo livre ligado à livre iniciativa estava equivocado, uma vez que existem o tempo de trabalho e outras tarefas e os que não relacionam com obrigações mas no qual ocorrem no tempo livre, permitindo que o mesmo aconteça. Então permite concluir que lazer é o tempo livre não são a mesma coisa. Cogitando lugar apropriado para a sua prática e isso ligado a esfera produtiva. De acordo com Marcellino para citar os aspectos educativos do lazer teríamos que considerá-lo como campo possível de contra-hegemonia. Então vale ressaltar a tradição gramsciniana e a pedagogia marxista - consciência da luta de classes-, através dos quais possibilitariam transformações significativas no campo do lazer. Nesse sentido - lazer-educação - é que Mascarenhas tenta aproximar de uma perspectiva de educação popular, pretendendo a construção de um mundo mais justo e melhor para se viver.

No segundo capítulo Mascarenhas parte das ideias de Paulo Freire para esboçar a pedagogia critica do lazer, uma nova proposta. Compreendendo a dimensão histórica do lazer e o mesmo como uma manifestação transitória, transformadora de homens, portanto para uma visão de homem, uma concepção de mundo, visando o lazer como prática da liberdade. Com uma percepção critica e consciente do conhecimento. Nesse capitulo é proposto uma nova estratégia no pensar o lazer. Parte em busca de referências encontra subsídios em Paulo Freire para aproximar o sujeito da sua história, na emancipação do homem. Busca assim 
problematizar um pensamento e pensá-lo para além. O lazer passa a ser fonte de valores e contradições. E a proposta central de Mascarenhas é uma intervenção do lazer-educação com grupos sociais para consolidar o lazer por meio de uma visão de homem e uma concepção de mundo. Cujo objetivo geral diz respeito na apreensão e reflexão do conhecimento em lazer pelo grupo e os objetivos específicos são pertinentes ao grupo trabalhado e os conteúdos a serem abordados. O tema e os conteúdos referem à historicidade. O método visa alcançar os objetivos. Sendo assim, propõe o êxito na intervenção. O avanço no ensinar o lazer esta na junção entre teoria e prática, na tentativa de construção de um método específico para uma abordagem do lazer com grupos sociais. E para superação das atuais propostas de lazer, materializa uma práxis político-pedagógica, destaque para tal o tema gerador, a rede temática e o ciclo temático. A princípio essa nova abordagem do lazer como prática da liberdade é possibilitada pela ação diagnóstica para o reconhecimento do grupo, um autodiagnóstico para a construção das possibilidades de trabalho. Identifica-se agora o tema gerador que liga o lazer ao contexto do grupo. Agora depois de um ciclo gerador de temas há uma preparação da rede temática para um verdadeiro diálogo com a realidade, com um jogo de perguntas e respostas, sendo o instrumento de organização e coordenação em todo o processo de investigação e as atividades.

A elaboração das atividades temáticas é resultante da investigação já realizada, novo versus o velho. Nas atividades de lazer há a situação-problema e a situação-limite. Após esses passos é elaborada a atividade preparatória, avaliativa e de recuperação. Onde a atividade preparatória precede a atividade temática, com a apresentação geral do tema gerador, norteando as demais atividades.A atividade avaliativa segue as atividades temáticas, como o próprio nome sugere refere-se a avaliação durante a prática, como as dificuldades encontradas, dentre outras. Já a atividade de recuperação é o momento de síntese e consolidação dos conteúdos e reflexões pertinentes á prática. A organização do ciclo temático sugere que os passos já citados sejam refeitos. Uma vez que agora há a organização dos conteúdos e das atividades, o ciclo é o modo de organização e de existência dos conteúdos temáticos e do lazer, e um ciclo sempre remete a outro. O autor trás a importância dos agentes de lazer ou educadores, que são capazes de maximizar o educativo do lazer, comprometido com a luta pela emancipação popular, ou seja, o homem emancipado, através das relações pedagógicas e hegemônicas inseparável da teoria do lazer. E os coordenadores e os agentes é o que conferem a 
aplicabilidade da "pedagogia crítica do lazer". E no livro no capítulo destinado ao lazer e intervenção: realidade e possibilidade para isso, busca a compreensão da realidade de meninos e meninas de rua, e a cultura.

Através da Sociedade Cidadão 2000, mapeou as crianças e adolescentes em situação de risco, classificando-os em sete categorias. Mostrando o quanto é pouco falado essa dura realidade e o quanto são marginalizados os meninos e meninas que na rua vivem. A cultura da rua, geralmente é a musical por meio do hap, no qual narram os acontecimentos e a vida na rua. $\mathrm{O}$ estatuto da criança e do adolescente também é empregado para mostrar o quanto a teoria se distorce da prática.

Mascarenhas ainda mostra a realidade de Goiás e de Goiânia, no qual essas crianças fazem de um tudo para tentar sobreviver. Então após a compreensão do grupo social em questãomeninos e meninas de rua de Goiânia-Mascarenhas exemplifica as possíveis atividades de lazer através da “ pedagogia crítica do lazer” e como agir em determinadas situações, para isso ele volta a estrutura já citada: o tema gerador, a rede temática, a atividade temática e a atividade preparatória, avaliativa e recuperação.Vale ressaltar que a exemplificação e feita mediante as atividades de gol-a-gol e futebol com suas alterações.

Em cena, entram os agentes de lazer/educação, que contam com pouca remuneração, tendo que contar com estudantes de educação física em convênio com a $\mathrm{UFG}^{1}$ e FUMDEC ${ }^{2}$, e apesar da inexperiência os profissionais contribuem muito para o projeto. Em um último momento o autor propõe uma nota de fim, apresentando a necessidade de novas propostas no campo do lazer, com uma visão ampla da dimensão do lazer, e para tal relata as dificuldades encontradas e as alegrias do projeto, dentre os relatos esta o da dificuldade quanto à rotatividade de educadores uma vez que a remuneração é baixa, então quando á uma consolidação e avanços logo há perdas em relação a pouca continuidade dos estagiários, as péssimas condições de trabalho dos educadores da FUMDEC, ausência do projeto políticopedagógico. E como ponto positivo é que o lazer-educação propicia a transformação de uma dada realidade, o projeto agente e oficinas pedagógicas.

\footnotetext{
${ }^{1}$ UFG - Universidade Federal de Goiás.

${ }^{2}$ FUMDEC - Fundação Municipal de Desenvolvimento Comunitário.

Conexões: revista da Faculdade de Educação Física da UNICAMP, Campinas, v. 11, n. 1, p. 252-258, jan./mar. 2013.256 ISSN: 1983-9030
} 
Há uma crescente importância para o lazer na sociedade moderna. Isto, pois, se pensarmos na vida cotidiana é fácil entendermos que o lazer é deixado de lado, uma vez que há falta de tempo é marcante, e a vida corriqueira e agitada faz com que deixemos de lado aquilo que foge de nossas obrigações, sendo assim o trabalho é sempre pensando em um primeiro momento, seguido por obrigações familiares, sociais, culturais dentre outras.

O lazer ganha slogan como algo compensatório, uma maneira de se extravasar o cotidiano, mas será mesmo que o lazer é a pura pratica do prazeroso? Lazer é recreação ou recreação é lazer? Onde começa e onde termina o seu lazer? A prática do lazer é generalista na sociedade? Essas são algumas indagações da qual fazemos, que são cabíveis devido esse ritmo frenético ao qual o lazer começa a se desenvolver, no qual pouco importa a designação do lazer, a prática do lazer ou o conhecimento acerca do lazer, isso torna-se puramente algo subjetivo.

Desse mesmo modo é que surge a importância de um lazer estruturado. Aonde ir ao clube, caminhar, assistir filme, comer, dentre outras coisas, tornam-se a maneira planejada de um divertimento, feito em seu tempo de descanso- tempo livre- como prazer, mas eis que lazer é prazer, mas nem tudo que é prazeroso é lazer.

Nesse contexto é que os profissionais de Educação Física ganham visibilidade, no corre-corre do dia-a-dia, propicia uma exaltação, a válvula de escape chamada lazer. Devido a isso, surge a importância de uma disciplina nos cursos de educação física que contemple os fundamentos do lazer e seus ensinamentos, capaz de promover debates acerca do mesmo, e de despertar nos acadêmicos o espírito de educador, ou seja, de professor para o lazer, fugindo do estereótipo de recreadores ou copiadores do conhecimento já apropriado para a área. Surge a necessidade de um novo olhar acerca do lazer e novas abordagens para o mesmo.

O lazer é parte integrante da formação acadêmica uma vez que se constitui em um campo de atuação dos profissionais de educação física, mas vale ressaltar que pouca ou quase nenhuma é a importância e o destaque que recebe. Mais simples do que destinar uma disciplina para debates e conhecimentos á respeito do lazer, é fragmentar o conhecimento e mesclá-lo a outras disciplinas, como disse mais simples, mas muito menos eficiente em termos de ensino e prática, ou seja, por isso surge à falta de preparação ou qualificação para se atuar no campo do lazer. Então atualmente é fácil entender a dificuldade em dissociar o lazer de mera 
recreação, da prática da oba-oba, da prática sem planejamento, uma mera prática pela prática. Falta-se conhecimento devido e adequado, e esse quadro tende a se alterar com mudanças na formação dos profissionais, e para isso espera-se que as instituições ensino superior repensem o seu currículo para maximizar o seu ensino.

Recebido em: 10 mar. 2013

Aceito em: 20 mar. 2013

Contato: Carolina Cavalcante de Paula prof.carolinacavalcante@hotmail.com 